\title{
Managing barriers of virtual communication in global new product development projects
}

\author{
Päivi Lohikoski, Jaakko Kujala, \\ Harri Haapasalo and Janne Härkönen
}

Industrial Engineering and Management, University of Oulu

P.O. Box 4610, FIN-90014, Finland

Email: Paivi.Lohikoski@Oulu.fi

Email: Jaakko.Kujala@Oulu.fi

Email: Harri.Haapasalo@Oulu.fi

Email: Janne.Harkonen@Oulu.fi

*Corresponding author

\section{Leena Ala-Mursula}

Institute of Health Sciences,

PL 5000, 90014 Oulun Yliopisto, Finland

Email: Leena-Ala-Mursula@Oulu.fi

\begin{abstract}
In virtual operating environments for new product development (NPD) increase the need to manage communication efficiently. The goal of communication is to reach a shared understanding; however, this is often challenging due to barriers that harm the communication process. Communication barriers typically cause misunderstandings and conflicts and hinder access to relevant information, causing delays in projects and some even fail in reaching their strategic or operational objectives. In addition to identifying the barriers, the main aim of the study was to discover ways of overcoming these barriers. We conducted a multi-method case study in a global telecommunications company. The theoretical base was built on virtual team literature and the theory of communication in virtual NPD teams' context. The key finding of this study is that main barriers to communication are egocentrism, information-sharing behaviour, inadequate language skills, mistrust, communication distortions and miscommunication. In addition, we identify specific managerial implications for organising communications in virtual projects.
\end{abstract}

Keywords: cross-cultural communication; virtual organisations; communication barriers; project management; global teams; new product development; NPD; virtual communication.

Biographical notes: Päivi Lohikoski is currently a doctoral student at the Industrial Engineering and Management at the Faculty of Technology at the University of Oulu. Her research interests are in knowledge management in virtual organisations and project communications. She received her MA in Information Studies from the University of Oulu, where she has worked as a University Lecturer and University Teacher 2005-2013. Her work experience has been concentrated on planning and teaching in e-learning projects and in addition she has several years work experience in the ICT industry in communication and documentation functions in $R \& D$. 
Jaakko Kujala is a Professor of Quality and Project Management in the University of Oulu, Department of Industrial Engineering and Management. $\mathrm{He}$ has an extensive industrial background in Metso Corporation in managing both customer delivery projects and internal development projects. He holds MSc in Information Technology and he received his doctoral degree in 2003 at the Department of Industrial Engineering and Management. His main research interests include network perspective to projects, project marketing and project business management.

Harri Haapasalo is a Professor at the Department of Industrial Engineering and Management since 1998. His list of publications contains more than 200 international publications, out of a total number of about 300 . His focus areas are industrial engineering and management, management of manufacturing oriented companies, product development and innovation operations.

Janne Härkönen received his BSc in Engineering Business Management (1st class honours) from the University of Greenwich in the UK and both his MSc in Process Engineering and his Dr (Tech) in Industrial Engineering and Management, from the University of Oulu, Finland. He has also studied in the University of North Carolina at Wilmington, USA. He has several years of experience from the IT industry, working in the UK, and also experience from the environmental technology industry, working in Finland. He has authored and co-authored some 30 journal articles, and also a number of other publications.

Leena Ala-Mursula acts as a Professor of Occupational Health at the University of Oulu. Her research interests are in the psychosocial backgrounds of workrelated health and well-being.

\section{Introduction}

Using virtual teams and global collaboration is a great opportunity for companies (Schall, 2013), however $50 \%$ of the distributed teams fail in reaching their strategic or operational objectives (Zakaria et al., 2004), which clearly presents that there are risks, that need to be managed properly (Alawamleh and Popplewell, 2012). Crucial issue in virtual teams is the need to manage such teams' communication effectively (Hofstede et al., 2010; Faraj et al., 2011).

Both global and co-located teams can exhibit high levels of virtuality (Kirkman and Mathieu, 2005) and several issues need to be considered when organising communication in global new product development (NPD) projects. There is usually high interdependency between departments, and the instability of the environment requires a large amount of information processing, which is often shared between teams and departments in virtual networks (Daft, 2010). It is crucial to recognise the pace and 
volume of communication, to organise and plan this wealth of information and its speed and synchronicity (Morreale et al., 2001). In addition to the availability of proper tools, the medium selected for communication is defined also by an individual's personality, organisational position and the current task (Rice and Case, 1983). The wide range of communication methods makes communication more complex than face-to-face interaction, however until now, studies have produced mixed results on information processing in virtual work settings (Faraj et al., 2011; Li, 2010). Our aim is to enrich the scientific discussion on virtual NPD project management and communication studies in the context of virtual teams through elaborating the existing theory. Also we offer multidisciplinary approach with new framework to the scientific discussion in this field.

Based on Connaughton and Shuffler's (2007) literature review, scholars are just beginning to study the influence of both cross-cultural issues and virtual collaboration on project success. New perspectives, frameworks and theories for analysing the global virtual work environment and communications offer new tools for both practitioners and academics. Communication has an effect on overall employee performance (Goris, 2007) and on project's success (Crane and Livesay, 2003; Welch and Jackson, 2007) making this study highly significant. The research questions for this study were formulated:

1 What are the typical communication barriers in virtual NPD?

2 How do communication barriers affect in different phases of the communication process?

3 How to overcome communication barriers?

We conducted a multi-method case study in a global telecommunications company with 12 virtually operating cross-cultural teams and their leaders in Finland, Poland, China and the USA. In addition, electronic survey data were collected and analysed. The data were taken from team members in Finland, Poland, India, China, Great Britain, Germany and the USA. Finally research results were presented and discussed in case company's workshops in order to validate the findings.

\section{Focal concepts and theoretical background}

According to media naturalness theory, human beings have been engineered to communicate primarily synchronously through facial expressions, body language and speech face to face. Therefore ambiguity and cognitive effort increase while psychological arousal decreases in virtual settings, which has an impact on teamwork. Thus, communication media should be designed primarily from these perspectives (Kock, 2005). However, face-to-face meetings are often difficult to arrange due to time differences (LeeKelley and Sankey, 2008) and financial restrictions, and therefore alternatives need to be identified to replace the richness of face-to-face communication (Hoefling, 2008). The main goal for communication in virtual NPD, therefore, is to achieve the highest possible naturalness at the lowest possible cost (Kock, 2005). Therefore the amount, usability, quality and accessibility of information and communication technology (ICT) tools also have an impact on communication (Miller, 2006; Zigurs, 2003). 
The mixture of asynchronicity and synchronicity of communication increase uncertainty related to the availability and accessibility of relevant information (Brown et al., 2007; Miller, 2006; Te'eni et al., 2007) and it is a crucial issue when organising communication within VTs (Jarvenpaa and Leidner, 1999; Zigurs, 2003; Faraj et al., 2011). Thus, a crucial issue for virtual team communication is to choose a proper method of communication for each purpose. Less urgent messages can be sent through asynchronous channels. However, due to time differences and geographical distance, synchronous communication for more urgent messages is not always an option (Brown et al., 2007; Miller, 2006). Asynchronicity has benefits: it leaves the opportunity to consider how to communicate and to plan content for the response. Looking for more information for the topic or consulting someone else before responding is also an option (Kirkman and Mathieu, 2005). Daft (2010) and Brashers (2001) argued that generally there is typically either too much or not enough information available.

Media richness theory proposes that the richest mode of communication is face to face, referring to the amount of social cues and languages and the ability to get immediate feedback and to provide explanations (Daft and Lengel, 1986; Te'eni et al., 2007). Typically, when exchanging emails, it is difficult to transmit the tone of voice or sarcasm; usually, the sender is not aware of this (Keysar, 2007). Furthermore, when communicating through email, vocal cues are unavailable for the interaction, which can inhibit communication of social and emotional content (Rice and Love, 1987; Te'eni | et al., 2007) and therefore ICT has changed communication patterns significantly (Rice and Case, 1983). However, it is possible to use 'emoticons' when writing and expressing emotions (Morreale et al., 2001). Also large numbers of messages with redundant or irrelevant content have added 'noise' to organisational communication (Stephens et al., 2013). Informal communication is very important for team's cohesiveness, which low media richness and asynchronicity usually impacts negatively (Martins et al.,2004).

\subsection{Communication process}

In the communication process, a group or person transmits information to another group or person in order to establish shared understanding about the topic (Morreale et al., 2001; Snowden and Boone, 2007). The communication process typically has three phases (Greenberg, 1999; Morreale et al., 2001; West and Turner, 2009):

1 Initiation phase: the message sender realises his or her need to communicate, constructs the message into a form that can be recognised by the receiver by selecting the appropriate words. Then sender chooses the methods and tools for communication and finally sends the message.

2 Transfer phase: the message moves from the sender to the listener.

3 Response phase: the listener receives the message and constructs a meaning for the message and plans the response. Finally, the listener sends a response back to the message sender. The communication process is a cycle that usually continues between team members throughout the life cycle of a project.

Listening skills and focusing on the content is important in the communication process (Sonnenberg, 1990). Morreale et al. (2001) reminded us that also listening as well requires three phases: receiving the message, constructing meaning and responding to the 
message. Communication has an impact on the distance between the message sender and receiver (Te'eni et al., 2007).

\subsection{Communication barriers}

In order to build successful global teams managers need to invest in collaboration and communication (Daft, 2010; Hoegl and Gemuenden, 2001). Common challenges for virtual organisations are language and cultural barriers, which can cause misunderstandings, resentment and mistrust (Hosseini et al., 2013; Daft, 2010). In addition, information sharing between departments and divisions within organisations can be a challenge due to protective behaviour, power use and a lack of shared goals. The distance between participants in a conversation can be physical, geographical or psychological (Maude, 2011).

Issues that may hinder communication have been identified as noise (West and Turner, 2009) and equivocality and ambiguity (Daft and Lengel, 1986), which has also been referred to as barriers in communication literature (Morreale et al., 2001). Noise harms the communication process in various ways as physical, physiological, psychological and semantic noise. Equivocality is connected to ambiguity in information, which can hinder information flow (Daft and Lengel, 1986). Equivocality can be related to linguistic or cultural differences in communication process (Wall and Callister, 1995). Individual's behaviour can be high or low in ambiguity for various reasons (Te'eni et al., 2007; Spitzberg, 1994). For example, silence can be interpreted in hesitation, confusion, anger or mere technical problems in teleconferences or during phone calls (Te'eni et al., 2007).

Egocentrism is a fundamental issue that harms communication. People often consider their own country or project to be the central one and act correspondingly (Hofstede et al., 2010). Other issues hindering communication include deliberate obfuscation, which has been linked to power tactics by Fairholm (2009) and Daft (2010). Common communication barriers in cross-cultural teams are related to miscommunication (Maude, 2011; Wall and Callister, 1995). In addition, communication distortions (Maude, 2011) and differences in information-sharing behaviours hinder communication (Huijser, 2006).

Previous interaction with others (Sonnenberg, 1990) and their unpredictable behaviour have been identified as significant factors in virtual team communications (Brashers,

2001; Keysar, 2007; Wall and Callister, 1995) in addition to relational history in organisations (West and Turner, 2009). Furthermore, Wall and Callister (1995) and Kankanhalli et al. (2007) argued that unresolved conflicts can be potential factors in harming interaction between people. High-quality communication in teams is sufficient, frequent, direct and open. In addition to task-related communication, informal, spontaneous information exchange among team members is crucial for creating and spreading new ideas (Hoegl and Gemuenden, 2001).

\subsection{Summary}

According to an extensive line of research (Morreale et al., 2001; Faraj et al., 2011; Hoegl and Gemuenden, 2001; Te'eni et al., 2007; Kirkman and Mathieu, 2005) the quality of communication is crucial and it is the interaction between individuals that counts (CookeDavies, 2002; Morreale et al., 2001). However, in projects the emphasis 
typically is on facts, details, status, requirements, and task related communication, whereas individual aspects of communication are in a less dominant role (Ramsing, 2009). Based on recent research presented in previous chapters it can be summarised that the main factors impacting communication in virtual NPD teams are asynchronicity vs. synchronicity related issues, media richness and media naturalness related issues. The solution so far has been to plan communication practices and processes and utilisation of ICT efficiently (de Jong et al., 2007; Faraj et al., 2011). However, as recent studies indicate, nevertheless some people find it easier to operate in virtual teams than others (Harwick et al., 2013; LeeKelley and Sankey, 2008; Lohikoski and Haapasalo, 2013; Reed and Knight, 2010).

Table 1 Communication barriers

Initiation and response phases in communication

Ambiguity and equivocality, strange accent, poor pronunciation (Maude, 2011), physical wellbeing and articulation problems (West and Turner, 2009).

Misunderstandings caused by linguistic or cultural ambiguity (Fairholm, 2009; Keysar, 2007; Sonnenberg, 1990; Wall and Callister, 1995).

Communication distortions, keeping things unclear on purpose (Daft and Lengel, 1986; Fairholm, 2009; Sonnenberg, 1990).

Power-related or social status-related attitudes towards other cultures, unconscious motives (Maude, 2011; Wall and Callister, 1995), psychological noise related to prejudices or feelings towards a person or a message (West and Turner, 2009; Fairholm, 2009).

Miscommunication, differences in nonverbal behaviour and language use (Keysar, 2007; Liebowitz and Wilcox, 1997; Maude, 2011; Wall and Callister, 1995), communication gap caused by different speech styles (Lewis, 2006).

Egocentric speech and understanding (Keysar, 2007).

Inability to listen (Lewis, 2006), considering one's own country as the central one and acting correspondingly (Hofstede et al., 2010).

Prior negative experiences and/or unresolved conflicts (Kankanhalli et al., 2007; Keysar, 2007; Sonnenberg, 1990; Wall and Callister, 1995).

Cultural differences in perception of sharing and dealing with information, 'knowledge is power' (Hosseini et al., 2013; Huijser, 2006; Kankanhalli et al., 2007; Morreale et al., 2001; Wall and Callister, 1995).

Amount of information being shared: the more information is shared, the more confused the recipient is (Keysar, 2007). Message overload and complexity (Morreale et al., 2001).

Mistrust, trust is a foundation for sharing knowledge. Without trust, there are challenges to knowledge sharing (Chen et al., 2011; Holste and Fields, 2012; Holton, 2001; Maude, 2011; Mitchell and Zigurs, 2009).

Noise technical problems: crackling or fading of sound (Maude, 2011). Physical noise that makes the message difficult to hear (West and Turner, 2009). Semantic noise from technical language, jargon and phrases that are unknown to the receiver (West and Turner, 2009).

Synchronicity vs. asynchronicity of communication (Brown et al., 2007; Kock, 2005; Miller, 2006)

Irrelevant, needlessly redundant messages (Stephens et al., 2013) 
In this study, we go deeper into the discussion of informal and formal communication, synchronous and asynchronous communication, utilising also media richness and media naturalness theories. We concentrate on the barriers that affect communication process itself, whether it is the question of formal or informal conversation. In addition, we suggest actions needed to overcome such barriers, which is among the aims of this study. The most common communication barriers are synthesised in Table 1.

\section{Multi-method case study: communication barriers in virtual NPD}

Case study approach was chosen, because it can create new practical knowledge, identify key factors and sources related to dynamic capabilities. It can also explain relationships in a broader sense by providing a structure for complex situations (Ridder et al., 2009). This research area needs more evidence and theoretical understanding, it shows contradictions and it is so far inadequate, which support selecting case study for a method (Eisenhardt, 1989). Yin (2009) emphasised the relevance of case for determining the 'how'-question, which is essential for qualitative research (Lee et al., 1999). The strength of the case study approach is to combine different types of data in order to obtain valid results (Eisenhardt, 1989).

This multi-method case study was designed to investigate communication barriers affecting communication among virtual teams. Our approach was to conduct literature review on virtual teams, project management and communications. Then literature-based semi-structured interviews, with electronic survey data were applied to identify key factors, competencies and logics (Ridder et al., 2009; Yin, 2009). This case study is significant from two perspectives. It uses a multidisciplinary approach to the communication process in virtual settings and it refines and elaborates existing theory. The key in theory elaboration is that empirical data serves to illustrate an existing general theoretical framework (Ketokivi and Choi, 2014) and combines existing theories. It does this by pointing out communication barriers and analysing managerial implications in a case study organisation. The opportunity for the reader is to gain a better understanding of the issues affecting communication, which is a significant contribution of the case study (Siggelkow, 2007).

In the research design phase, the methods and the themes for the interviews were designed and qualitative and quantitative data were used to complement each other (Birkinshaw et al., 2011). Using different data and methods in the same study tests the validity of research methods and helps to highlight any inconsistencies in the results (Patton, 2001). The researchers and the case organisation have a long partnership, which increases the level of trust between the informants and the researchers. Figure 1 describes the case study design. 
Figure 1 Case study design

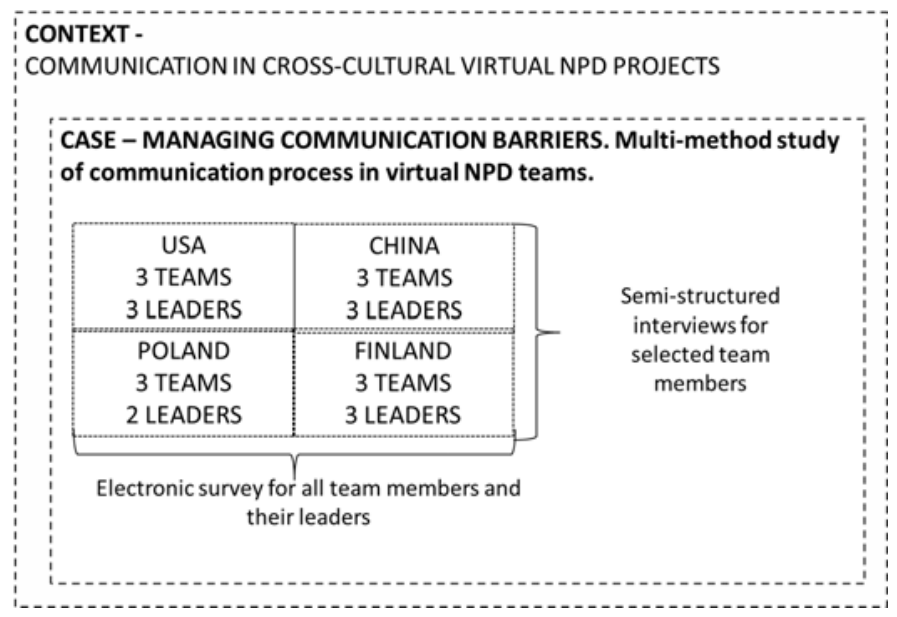

Qualitative semi-structured interviews: The themes for the interviews were based on communication practices in the virtual project, the division which was also used in processing the research data. Test interviews were first conducted on selected engineers in the case company to test the form and validity of the questions. After revising the questions, interviews were conducted at sites in the USA, Finland, China and Poland to the selected team members based on their availability and willingness to participate. The teams in Finland were interviewed face to face and via teleconference. The teams in the USA, China and Poland were interviewed in a web conference, which is similar to a face-to-face meeting. Each interview was recorded, transcribed and analysed. In each interview there were 3-6 participants, from teams that had 10-20 team members. Qualitative data were rich, diverse, complex and subtle as described by (Seale et al., 2004) of good qualitative data. Versatile research data enhanced gaining a deeper understanding of a case (Yin, 2009). Appendix 4 presents the interview themes and study units of communication in different phases of NPD projects and the issues from where the interview questions were developed. Finally, the results were analysed, compared and enriched with the survey data.

Electronic survey: quantitative data were collected via an electronic survey. Survey questionnaires were also tested by five different case organisation members to detect possible flaws. After minor improvements, informants were invited to participate in the survey via email. Two reminders were sent to potential participants during the study. Two online electronic surveys were active for five months. Ninety-four employees completed the questionnaire, for a $69 \%$ response rate. We used Webropol, an internet-based survey program. The questionnaire was built on interview themes and used a four-point Likert scale. Data were processed using MS Excel.

Validation of the results: the research results were validated in workshops that were held in the case company. The main research results were presented and discussed with the informants and their randomly chosen team members in five separate workshops. 


\subsection{Organisation}

The case study organisation is a leading global enabler of telecommunications services operating in 150 countries. The case organisation was selected for the study because it has a multinational and multisite virtual way of working. We used semi-structured interviews with selected team members and their leaders based on their availability. The informants were a rich selection of virtual team members including line managers, project managers, program managers, senior specialists and chief engineers. The informants worked for several different projects, which were in different phases. Informants were advised to answer the questions based on their work experience in virtual projects in general, rather than based on the current project. The characteristics of the informants are described in more detail in Appendix 2.

\subsection{Results: communication barriers affecting the communication process}

\subsubsection{Initiation phase}

The most common communication barriers related to the initiation phase in communication based on the interviews include egocentrism, miscommunication, information-sharing behaviour and previous interaction. More specifically, the inability to choose the proper methods for each purpose causes an overuse of emails even for issues that would require methods that enable rich communication, such as web conferencing. There were personal differences of opinion on showing facial expressions during conversations. Some informants preferred not to see the other person while talking; for others, it was important to feel the social presence of the colleague. Other issues concerning information sharingbehaviour were the clarity of shared goals and norms in communication between hardware (HW) and software (SW). In particular, the clarity of shared goals between sites disappeared whenever there were delays to schedules, changes in the original project plans or technical problems. All sites excluding Poland recognised this challenge and its effects on information-sharing behaviour. However, information-sharing challenges between Polish teams were also mentioned with reference to other sites. Communication methods were chosen, and messages were formed based on own cultural preferences. Relationshipbased problems also caused problems with miscommunication and information-sharing behaviour. Survey results on the communication barriers are presented in Appendix 2.

\subsubsection{Response phase}

Inadequate language skills were considered the greatest barrier to communication, which also increased the amount of time used for communication. In addition, equivocality, ambiguity and miscommunication caused by differences in technical knowledge and cultural background can harm the communication process. Unwillingness or inability to listen may also harm communication. Geographical dispersion and time differences were described as major challenges. It is very difficult to find mutually convenient times for virtual meetings between China and USA. Meetings usually take place in the middle of the night or very early in the morning. As a result, some virtual team members do not find it easy to participate in all the meetings and often miss relevant information. Employees often work on several different projects; therefore, according to the 
interviews, prioritising is often done at the expense of a virtual project. Based on the interviews, virtual meetings were considered inefficient, especially when they were used primarily for information sharing or when the length of the meeting and the number of participants were considered excessive.

\subsubsection{Initiation and response phases}

Communication barriers including egocentrism, inadequate language skills, equivocality and previous interaction are also relevant to the listener. Cultural issues were highlighted, both in terms of country and corporate culture, which were seen as major influences. The leaders in the case company saw cultural knowledge as a cornerstone when communicating with global teams because there are no reliable tools or metrics to describe potential problems in an accurate and timely manner during the course of the project. In addition, skills in the company language, creativity and the originality of the team members should be taken into account when sharing tasks, evaluating results and giving feedback. It was considered important for the leaders to be able to get the information directly from the employees in a timely manner. However, this is not always easy when operating across different sites, time zones and cultures. The survey results concerning these issues are described in Appendix 1.

The US site was the most multicultural, consisting of 26 different nationalities. All the informants mentioned that, in USA, nationality or cultural issues were not considered as having a major impact on the team's performance. In projects carried out between Finland and USA, cultural differences were not seen as significant due to a long (15-20 years) history of work experience in shared projects, which made interaction easier. According to the US teams, team performance is based more on corporate culture or cooperation between different kinds of personalities than on national cultures. However, cultural knowledge was still considered significant by all the informants. In particular, all the leaders in the USA emphasised the significance of acknowledging cultural background when giving feedback. Moreover, sharing and assigning tasks has to be done very differently across different sites. As a leader in Finland commented, communication with employees in China, Poland, Germany and the USA needs to be understood correctly. Team leaders considered cultural variety as adding richness, and they appreciated it. However, this was only the case if special cultural characteristics were well known, as leader C in Finland commented:

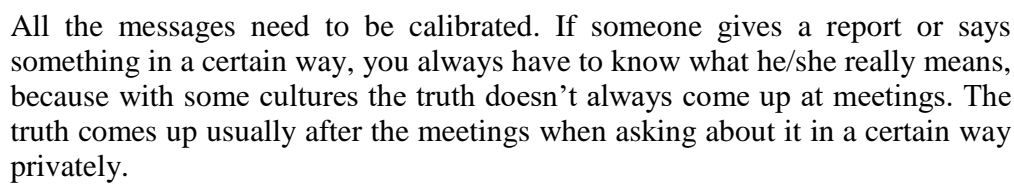

One of the most significant findings was the strong reliance on asynchronous communication even in complex technical issues and conflicts. This was related to time differences, as well as to an inability to choose the best tools for each purpose. Unclear communication with no clear focus leads to inefficiency in emails and virtual meetings. Email-related problems are tangled together with relationship-based conflicts, which result from unclear messages that are easy to misinterpret. All the informants saw cultural background as having a significant influence on both sending and receiving information, as leader B in Poland explained: 
People can get different understandings of the same messages, depending on the culture, depending on the background, and depending on the skills. It is so ... but this is quite universal. It's always happening.

Using a variety of ways to communicate requires flexibility, patience, accountability, cultural knowledge, listening skills and verbal and written English skills, which were mentioned by most of the informants as fundamental skills for a virtual team member. Patience, accountability and flexibility were considered particularly significant. The communication barriers are summarised in Table 2.

Table 2 Communication barriers

Findings: initiation and response phase

Egocentrism

- The working culture of one's own site is considered the most efficient.

- Lack of team building causes a lack of team spirit in virtual teams.

- Strong team spirit and trust among co-located teams enhances coalitions and competition with other sites.

Mistrust

- Previously unresolved conflicts cause mistrust.

- Lack of team building and lessons learned challenge development of trust in virtual teams. Information-sharing behaviour

- Large numbers of e-mails inflate information.

- Unstructured messages with excessive length can lose the actual message.

- Various tools and databases challenge accessibility to documents

- Lack of shared goals between organisations when sharing tasks and resources

- Time differences harm communication synchronicity and the transfer of tacit knowledge.

- The actual project status is difficult to investigate in cross-cultural virtual meetings due to cultural differences.

- Unwillingness to take the opinions of others into consideration in decision making in virtual meetings

- Accessibility and data-sharing problems with subcontractors and vendors

- Social collaboration platforms exist, but they are not systematically utilised.

Previous interaction

- Background knowledge about other cultures' communication characteristics is not adequate.

- Team building and lessons learned meetings have not been conducted properly. In virtual teams, there was no team spirit.

- Unresolved conflicts and prior negative experiences affect collaboration negatively.

Communication distortions

- Competition between sites causes protective behaviour.

- Communicating and for not communicating was considered as a source of power. 
Table 2 Communication barriers (continued)

Findings: initiation and response phase

Miscommunication

- Inadequate language skills cause misunderstandings, and communication consumes more time.

- In some cases, reports and documentation can be in a foreign language.

- Inability to express thoughts concisely and briefly while taking recipient into account.

Equivocality and ambiguity

- Difficulty in understanding the message because of differences in technical competence and background

- Messages can be misunderstood and/or misinterpreted due to inadequate English skills.

- Language issues can cause problems and conflicts.

- Native English speakers can dominate conversations and meetings.

- Native English speakers tend to consider effective communication equivalent to "a lot of communication".

- Native English speakers were considered to dominate meetings because of their advanced company language skills.

- Actions needed by individuals are sometimes unclear in mass e-mails.

- Unstructured and long meetings are a challenge to efficient information processing and control.

Findings: transfer phase

Asynchronicity and noise

- Time differences harm the communication

- Noise caused by technical problems related to ICT tools

- Tool-related connectivity problems sometimes exist, typically in interaction with teams in China.

\section{Discussion}

This study contributes theoretically to the field of virtual teams and project management and it expands theory by offering an in-depth multidisciplinary approach in virtual team project communication's context. The finding of this study is that most barriers are related different phases in communication process and personal factors such as inadequate language skills, egocentrism, communication distortions, information-sharing behaviour and miscommunication rather than tool-related issues. Barriers of communication harm the communication process when constructing the message and choosing the communication method and when receiving the message and giving feedback. It is useful to view communication as a process with three phases: the initiation phase, the transfer phase and the response phase. These phases are more complex in a virtual NPD environment. The main findings, which are explained in this chapter, were evaluated at the company workshops and considered to provide tools for coordinating virtual team communication processes more effectively. 


\section{Initiation phase and response phase}

The first barrier usually appears at the initiation phase. In such a case, the tools and methods for communicating might be wrong depending on the task. Discussing complex technical issues or resolving conflicts through asynchronous tools can be challenging and time consuming. When communicating through e-mail, interaction may lack emotional content, which can inhibit communication (Rice and Love, 1987; Te'eni et al., 2007). The nature of the knowledge, tasks or information to be communicated should be understood and planned. Appropriate tools should be chosen for that purpose. In asynchronous communication, the greatest barriers were related to emails and documentation. Other barriers related to information-sharing behaviour were email practices. Large numbers of e-mails cause inflation in the urgency of actions needed, and it is not always clear who is responsible for tasks delegated via email. Unstructured messages with excessive length can lose the actual message and cause conflicts, as noted by Lohikoski and Haapasalo (2013) and Brown et al. (2007). However, for some team members, communication with emotional content was easier to handle through email than face to face. The leaders also considered e-mail a safer and easier way to share tasks.

Miscommunication caused by language use has been identified by Wall and Callister (1995) and Liebowitz and Wilcox (1997) as one of the most common problems in team communication. This was also recognisable in the case company. Inadequate language skills cause misunderstandings, and communication with those who have inadequate language skills takes more time than communication between native speakers and speakers who are fluent in the company language. Similar barriers to the communication process have also been recognised by Daft and Lengel (1986), Huijser (2006), Rice and Love (1987) and Wall and Callister (1995). To sum up, the different methods of using and interpreting language and ICT tools make communication complex in virtual settings (Morreale et al., 2001).

The case company's strategy to have key performance indicators (KPIs) for each site increases protective, egocentric behaviour at the expense of information sharing. The lack of shared goals is in line with Daft's (2010) perceptions on common challenges in multinational global teams. Sites with a long history of working together had fewer problems with cooperation than sites with less experience in global projects. Brashers (2001) also stated that previous interaction can either increase or decrease uncertainty.

Cultural knowledge was considered crucial for the virtual team members, particularly for the virtual team leader. It was significant in sharing tasks and giving feedback. In addition, it was considered vital to be able to express thoughts explicitly and briefly in virtual settings while taking the recipient into account, which is in line with previous research by Lohikoski and Haapasalo (2013). According to Maude (2011), strange accents and poor pronunciation can cause problems in virtual communication. Different company cultures caused by past mergers can increase communication distortions (Maude, 2011).

Previous interaction has been identified earlier as a common barrier by Sonnenberg (1990). Furthermore, Wall and Callister (1995) argued that unresolved conflicts in the past can harm interaction in the present. This was also clearly indicated in this study. However, previous interaction can also add predictability and enhance communication, as the teams in Finland and USA described. Their managers and team members had up to 15 years of experience in working together in virtual teams, which made interaction easier. Brashers (2001) concluded that people either avoid communication or increase 
communication to manipulate uncertainty to suit their needs. This perception was also valid in this study. Differences in communication were obvious, particularly when comparing Chinese and American colleagues. Team members from the USA considered more communication beneficial, whereas their Chinese colleagues thought it would be more beneficial to communicate less but more clearly, using simpler words and sentences.

Messages and tone of voice can be misinterpreted and misunderstood due to inadequate English language skills, which can even be a cause for conflict, as Kankanhalli et al. (2007) found. In addition, native English speakers were considered to dominate the meetings because of their more advanced company language skills. Native English speakers, however, did not do this deliberately; in some cases, they found it frustrating to communicate with team members with less adequate language skills. Decision making in virtual meetings was considered challenging for the same reasons. This concurs with what Huijser (2006) found when working with global virtual teams.

\section{Transfer phase}

Communication barriers related to the transfer phase were technical problems and asynchronicity-related problems. Brown et al. (2007) and Hertel et al. (2005) argued that a project needs rules for communication, such as rules on what information is shared and when and how team members are expected to communicate. The unavailability and inaccessibility of information has been identified as one of the factors increasing uncertainty (Brown et al., 2007; Miller, 2006; Te'eni et al., 2007).

To sum up, communication barriers cause delays in projects, increase the amount of conflict due to misunderstandings and decrease the availability of information. In addition, competition between sites is increased, and communication consumes more time. Using a variety of ways to communicate requires flexibility, patience, cultural knowledge, listening skills and verbal and written English skills, which were mentioned by all informants as fundamental skills for a virtual team member.

\subsection{Managerial implications}

We have offered an in-depth multidisciplinary approach to managing virtual team communication and therefore we can provide managerial tools for managing communications in virtual NPD projects. Clear information about interactions, goals, procedures and outcomes are especially significant in times of uncertainty in organisational change, technological innovation, redundancies, retraining or in situations where creative new business solutions are needed.

Communication training would be useful to enhance language skills, ability to choose proper tools for each purpose, to learn e-mail etiquette to increase the ability to write clear, informative and succinct e-mails to reduce equivocality and uncertainty. Communication training could also include training for native speakers on using simpler words, repeating the message and reducing the amount of communication. People often expect to communicate better when they share more information than when they share less. However, as indicated in previous research, the more information people share, the more they confuse the message receiver (Keysar, 2007). Better knowledge and training on the effective management of virtual meetings would also be beneficial. Company 
language skills and use should be mandatory for all company documentation and in crosscultural meetings.

Information-sharing behaviour is a significant aspect of virtual teams in knowledgeintensive organisations. Team members should be trained in and made aware of appropriate communication tools and methods for each purpose. Rice (1992) also stated that it might be beneficial to integrate both media use and media awareness more closely into organisational communication channels. Previous research (Kock, 2005) has indicated that relying primarily on asynchronous tools consumes significantly more time than offering face-to-face options. Modern web conferences offer similar communication options to face-to-face meetings and should be used more.

Virtual social skills including cultural sensitivity and knowledge are essential. The ability to understand the message sender's point of view and cultural background helps decrease the communication barriers related to equivocality and miscommunication. Communication distortion and attitudes towards other cultures are sometimes unconscious and can be harmful if not recognised by managers and team members and processed among global teams. Therefore, cultural training is recommended as part of the virtual teambuilding process. In addition to language training, regular feedback and reward practices are recommended. It is vital to support communication, as it is the foundation for the success of individuals and organisations (Greenberg, 1999).

Recognising achievement and organising 'lessons learned' events for the teams can help future projects by showing respect and consideration for the needs of team members. Reintegration often takes place; therefore, careful disbanding is important (Mukherjee et al., 2012). In virtual teams, the consideration of team members' needs is easy to forget. As a result, mistrust, egocentrism and experience of previous interactions can result into communication barriers.

\subsection{Conclusions and future research}

The current research project has attempted to build a framework for studying communication barriers in virtual organisations among virtual product development teams. In the case organisation, these issues relate mainly to egocentrism, information-sharing behaviour, miscommunication, communication distortions, previous interaction and equivocality. Barriers that affect the communication process could be overcome with systematic training in communication skills. Feedback and rewards for collaborative behaviour are needed in addition to a focus on cultural awareness, sensitivity and training. Furthermore, constant reminders about shared goals and rewards for collaborative behaviour and high-quality communication are cornerstones for efficient performance among virtual team members in NPD. The clarity of shared goals and norms needs more focus in virtual NPD where the working environment is turbulent and high in uncertainty.

Although this research has been carefully planned and conducted with the highest standards, some caution should be used when evaluating the relevance of the study. There are some limitations. While qualitative data provide rich information with in-depth views about the organisations that have been researched, it should be noted that the empirical data were collected from a single case company. However, the case company has a long history and experience in virtual projects. The managers and virtual team members who participated in this study have a variety of experience in virtual projects. Therefore, information from the survey and the interviews can be considered rich in many ways.

This research topic is highly relevant due to the increased need to establish global teams and to enhance the efficiency of virtual communication. However, new multi- method studies are needed to study these complex issues, to shed more light on the development of trust and to highlight issues related to virtual collaboration competencies and power use. In addition, future studies should focus on a number of different companies and a broad spectrum of companies in different fields of business and in different age groups in terms of using ICT. Moreover, the complexity of the communication process and information sharing provide a variety of possibilities for more in-depth studies of the collaboration of global teams. 


\section{References}

Alawamleh, M. and Popplewell, K. (2012) 'Risk in virtual organisation: a case study', International Journal of Networking and Virtual Organisations, Vol. 11, No. 2, pp.142-155.

Birkinshaw, J., Brannen, M.Y. and Tung, R.L. (2011) 'From a distance and generalizable to up close and grounded: reclaiming a place for qualitative methods in international business research', Journal of International Business Studies, Vol. 42, No. 1, pp.573-581.

Brashers, D.E. (2001) 'Communication and uncertainty management', Journal of Communication, Vol. 51, No. 3, pp.477-497.

Brown, K.M., Huettner, B. and James-Tanny, C. (2007) Managing Virtual Teams: Getting the Most from Wikis, Blogs, and Other Collaborative Tools, Wordware Publishing Inc., Texas.

Chen, C.C., Wu, J., Ma, M. and Knight, M.B. (2011) 'Enhancing virtual learning team performance: a leadership perspective', Human Systems Management, Vol. 30, No. 4, pp.215-228.

Connaughton, S.L. and Shuffler, M. (2007) 'Multinational and multicultural distributed teams: a review and future agenda', Small Group Research, Vol. 38, No. 3, pp.387-412.

Cooke-Davies, T. (2002) 'The "real” success factors on projects', International Journal of Project Management, Vol. 20, No. 3, pp.185-190.

Crane, A. and Livesey, S. (2003) 'Are you talking to me? Stakeholder communication and the risks and rewards of dialogue', in Andriof, J., Waddock, S., Rahman, S. and Husted, B. (Eds.): Unfolding Stakeholder Thinking 2: Relationships, Communication, Reporting and Performance, pp.39-52, Greenleaf, Sheffield, UK.

Daft, R.L. (2010) Understanding the Theory and Design in Organizations, 10th ed., China Translation and Printing Services Ltd, China.

Daft, R.L. and Lengel, R.H. (1986) 'Organizational information requirement, media richness and structural design', Management Science, Vol. 32, No. 5, pp.554-571.

de Jong, R., Schalk, R. and Curseu, P.L. (2007) 'Virtual communication, conflicts and performance in teams', Team Performance Management, Vol. 14, Nos. 7-8, pp.364-380.

Eisenhardt, K.M. (1989) 'Building theories from case study research', The Academy of Management Review, Vol. 14, No. 4, pp.532-550.

Goris, J.R. (2007) 'Effects of satisfaction with communication on the relationship between individual-job congruence and job performance/satisfaction', Journal of Management Development, Vol. 26, No. 8, pp.737-752.

Greenberg, J. (1999) Managing Behavior in Organizations, Prentice-Hall Inc., Upper Saddle River, New Jersey.

Fairholm, G.W. (2009) Organizational Power Politics. Tactics in Organizational Leadership, ABCCLIO.

Faraj, S., Jarvenpaa, S.L. and Majchrzak, A. (2011) 'Knowledge collaboration in online communities', Organisation Science, Vol. 22, No. 5, pp.1124-1239.

Harwick, J., Anderson, A. and Cruickshank, D. (2013) 'Trust formation processes in innovative collaborations: networking as knowledge building practices', European Journal of Innovation Management, Vol. 16, No. 1, pp.4-21.

Hertel, G. Geister, S. and Konradt, U. (2005) 'Managing virtual teams: a review of current empirical research', Human Resource Management Review, Vol. 15, pp.65-95.

Hoefling, T. (2008) 'The three-fold path of expanding emotional bandwidth in virtual teams', in Nemiro, J., Beyerlein, M., Bradley, L. and Beyerlein, S. (Eds.): The Handbook of High Performance Virtual Teams: A Toolkit for Collaborating Across Boundaries, John Wiley \& Sons, San Francisco, USA.

Hoegl, M. and Gemuenden, H.G. (2001) 'Teamwork quality and the success of innovative projects: a theoretical concept and empirical evidence', Organization Science, Vol. 12, No. 4, pp.435449.

Hofstede, G., Hofstede, G.J. and Minkov, M. (2010) Cultures and Organizations: Software of the Mind. Intercultural Cooperation and Its Importance for Survival, 3rd ed., McGraw-Hill, New York.

Holton, J.A. (2001) 'Building trust and collaboration in a virtual team', Team Performance Management: An International Journal, Vol. 7, No. 3-4, pp.36-47.

Holste, S.J. and Fields, D. (2010) 'Trust and tacit knowledge sharing and use', Journal of Knowledge Management, Vol. 14, No. 1, pp.128-140.

Hosseini, R.M., Zuo, J., Chileshe, N. and Baroudi, B. (2013) 'A conceptual meta-framework for managing multicultural global virtual teams', International Journal of Networking and Virtual Organisations, Vol. 12, No. 4, pp.310-330.

Huijser, M. (2006) The Cultural Advantage: A New Model for Succeeding with Global Teams, Intercultural Press, Amsterdam.

Jarvenpaa, S.L. and Leidner, D.E. (1999) ‘Communication and trust in global virtual teams', 
Organization Science, Vol. 10, No. 6, pp.791-816.

Kankanhalli, A., Tan, B.C.Y. and Wei, K. (2007) 'Conflict and performance in global virtual teams', Journal of Management Information Systems, Vol. 23, No. 3, pp.237-274.

Ketokivi, M. and Choi, T. (2014) 'Renaissance of the case research as a scientific method', Journal of Operations Management, Vol. 32, No. 5, pp.232-240.

Keysar, B. (2007) 'Communication and miscommunication: the role of egocentric processes', Intercultural Pragmatics, Vol. 4, No. 1, pp.71-84.

Kirkman, B.L. and Mathieu, J.E. (2005) 'The dimensions and antecedents of team virtuality', Journal of Management, Vol. 31, No. 5, pp.700-718.

Kock, N. (2005) 'Media richness or media naturalness? The evolution of our biological communication apparatus and its influence on our behavior toward e-communication tools', IEEE Transactions on Professional Communication, Vol. 48, No. 2, pp.117-130.

Li, W. (2010) 'Virtual knowledge sharing in a cross-cultural context', Journal of Knowledge Management, Vol. 14, No. 1, pp.38-50.

Liebowitz, J. and Wilcox, L.C. (1997) Knowledge Management and Its Integrative Elements, Library of Congress Cataloging-in-Publication Data, CRC Press, Boca Raton, Florida.

Lee-Kelley, L. and Sankey, T. (2008) 'Global virtual teams for value creation and project success: a case study', International Journal of Project Management, Vol. 26, No. 1, pp.51-62.

Lee, T.W., Mitchell, T.R. and Sablynski, C.J. (1999) 'Qualitative research in organizational and vocational psychology, 1979-1999', Journal of Vocational Behavior, Vol. 55, pp.161-187.

Lewis, R.D. (2006) When Cultures Collide. Leading Across Cultures, 3rd ed., Nicholas Brealey Publishing, London, UK. 
Lohikoski, P. and Haapasalo, H. (2013) 'Virtual competencies and knowledge transfer in global NPD', International Journal of Management, Knowledge and Learning, Vol. 2, No. 2, pp.185207.

Martins, L.L., Gilson, L.L. and Maynard, T.M. (2004) 'Virtual teams: what do we know and where do we go from here?', Journal of Management, Vol. 30, No. 6, pp.805-835.

Maude, B. (2011) Managing Cross-Cultural Communication: Principles and Practice, Palgrave MacMillan, Great Britain.

Miller, K. (2006) Organizational Communication: Approaches and Processes, 4th ed., Thomson Wadsworth, Belmont, California.

Mitchell, A. and Zigurs, I. (2009) 'Trust in virtual teams: solved or still a mystery?', The Database for Advances in Information Systems, Vol. 40, No. 3, pp.61-83.

Morreale, S.P., Spitzberg, B.H. and Barge, K.J. (2001) Human Communication: Motivation, Knowledge and Skills, Thomson Wadsworth, Belmont, California.

Mukherjee, D., Lahiri, S., Mukherjee, D. and Billing, T.K. (2012) 'Leading virtual teams: how do social, cognitive, and behavioral capabilities matter?', Management Decision, Vol. 50, No. 2, pp.273-290.

Patton, M. (2001) 'Evaluation, knowledge management, best practices, and high quality lessons learned', American Journal of Evaluation, Vol. 22, No. 3, pp.329-336.

Ramsing, L. (2009) 'Project communication in a strategic internal perspective', Corporate Communications: An International Journal, Vol. 14, No. 3, pp.345-357.

Reed, A.H. and Knight, L.V. (2010) 'Effect of a virtual project team environment on communicationrelated project risk', International Journal of Project Management, Vol. 28, No. 5, pp.422-427.

Rice, R. (1992) 'Task analyzability, use of new media, and effectiveness: a multi-site exploration of media richness', Organization Science, Vol. 3, No. 4, pp.475-500.

Rice, R.E. and Case, D. (1983) 'Computer-based messaging in the university: a description of use and utility', Journal of Communication, Vol. 33, No. 1, pp.131-152.

Rice, R.E. and Love, G. (1987) 'Electronic emotion: socioemotional content in a computer-mediated communication network', Communication Research, Vol. 14, No. 1, pp.85-108.

Ridder, H-G., Hoon, C. and McCnadless, A. (2009) 'The theoretical contribution of case study research to the field of strategy and management', in Bergh, D.D. and Ketchen Jr., D.J. (Eds.): Research Methodology in Strategy and Management, Emerald JAI Press, UK.

Schall, D. (2013) 'Socially-based brokerage and composition in virtual communities', International Journal of Networking and Virtual Organisations, Vol. 12, No. 3, pp.251-281.

Seale, C., Gobo, G., Gubrium, J. and Silverman, D. (2004) Qualitative Research Practice, Cromwell Press Ltd, SAGE Publications Ltd, The Trowbridge, Wiltshire.

Siggelkow, N. (2007) 'Pursuation with case studies', Academy of Management Journal, Vol. 50, No. 1, pp.20-24.

Snowden, D.J. and Boone, M.E. (2007) 'A leader's framework for decision making', Harvard Business Review, Vol. 85, No. 11, pp.1-9.

Sonnenberg, F.K. (1990) 'Barriers to communication', The Journal of Business Strategy, Vol. 11, No. 4, pp.56-59.

Spitzberg, B.H. (1994) 'The dark side of (in)competence', in Cupach, W.R. and Spitzberg, B.H. (Eds.): The Dark Side of Interpersonal Communication, pp.25-49, Erlbaum, Hillsdale, NJ.

Stephens, K.K., Barrett, A.K. and Mahometa, M.J. (2013) 'Organizational communication in emergencies: using multiple channels and sources to combat noise and capture attention', Human Communication Research, Vol. 39, pp.230-251.

Te'eni, D., Carey, J. and Zhang, P. (2007) Human Computer Interaction: Developing Effective Organizational Information Systems, John Wiley \& Sons, Inc., Hoboken, New Jersey. 
Wall, J.A. and Callister, R.R. (1995) 'Conflicts and its management', Journal of Management, Vol. 21, No. 3, pp.515-558.

Welch, M. and Jackson, P.R. (2007) 'Rethinking internal communication: a stakeholder approach', Corporate Communications An International Journal, Vol. 12, No. 2, pp.177-198.

West, R. and Turner, L.H. (2009) Understanding Interpersonal Communication: Making Choices in Changing Times, 2nd ed., Wadsworth Cengage Learning, Boston.

Zakaria, N., Amelinckx, A. and Wilemon, D. (2004) 'Working together apart? Building a knowledge sharing culture for global virtual teams', Creativity and Innovation Management, Vol. 13, No. 1, pp.15-29.

Zigurs, I. (2003) 'Leadership in virtual teams: oxymoron or opportunity?', Organizational Dynamics, Vol. 31, No. 4, pp.339-351.

Yin, R.K. (2009) Case Study Research: Design and Methods, 4th ed., Sage Publications, California.

\section{Appendix 1}

\begin{tabular}{|c|c|c|c|c|}
\hline Statement & Disagree & $\begin{array}{l}\text { Partly } \\
\text { disagree }\end{array}$ & $\begin{array}{l}\text { Partly } \\
\text { agree }\end{array}$ & Agree \\
\hline $\begin{array}{l}\text { My information and communication technology } \\
\text { (ICT) skills are sufficient for working in virtual } \\
\text { teams. }\end{array}$ & 1 & 5 & 26 & 67 \\
\hline $\begin{array}{l}\text { I have good communication skills in virtual } \\
\text { environments. }\end{array}$ & 0 & 11 & 41 & 48 \\
\hline $\begin{array}{l}\text { It is not a problem that I can't see facial } \\
\text { expressions and gestures in virtual meetings. }\end{array}$ & 9 & 30 & 41 & 21 \\
\hline $\begin{array}{l}\text { Transferring advanced professional knowledge } \\
\text { via ICT is not a problem. }\end{array}$ & 11 & 29 & 43 & 18 \\
\hline ICT tools support and make my work easier. & 2 & 19 & 47 & 32 \\
\hline $\begin{array}{l}\text { The virtual work environment enhances my job } \\
\text { satisfaction. }\end{array}$ & 11 & 41 & 38 & 10 \\
\hline $\begin{array}{l}\text { Managers perform efficiently in virtual } \\
\text { meetings. }\end{array}$ & 7 & 32 & 47 & 14 \\
\hline $\begin{array}{l}\text { I have been introduced to the company } \\
\text { guidelines of working in virtual teams }\end{array}$ & 29 & 24 & 30 & 18 \\
\hline $\begin{array}{l}\text { The practices of virtual work environment get } \\
\text { routinely discussed as the teams start working }\end{array}$ & 19 & 26 & 37 & 18 \\
\hline $\begin{array}{l}\text { Team members are familiar with the company } \\
\text { guidelines of working in virtual teams }\end{array}$ & 19 & 37 & 31 & 13 \\
\hline I can affect virtual meetings times between sites & 5 & 23 & 51 & 21 \\
\hline Managers perform efficiently in virtual meetings & 7 & 32 & 47 & 14 \\
\hline $\begin{array}{l}\text { Virtual meetings are well structured and useful } \\
\text { for me }\end{array}$ & 7 & 22 & 49 & 22 \\
\hline
\end{tabular}




\section{Appendix 2}

Characteristics of the informants based on the survey

Work experience in virtual projects:

- $54 \%$ had less than 10 years of experience

- $29 \%$ had 10-14 years of experience

- $11 \%$ had 15-19 years of experience

- $7 \%$ had over 20 years of experience
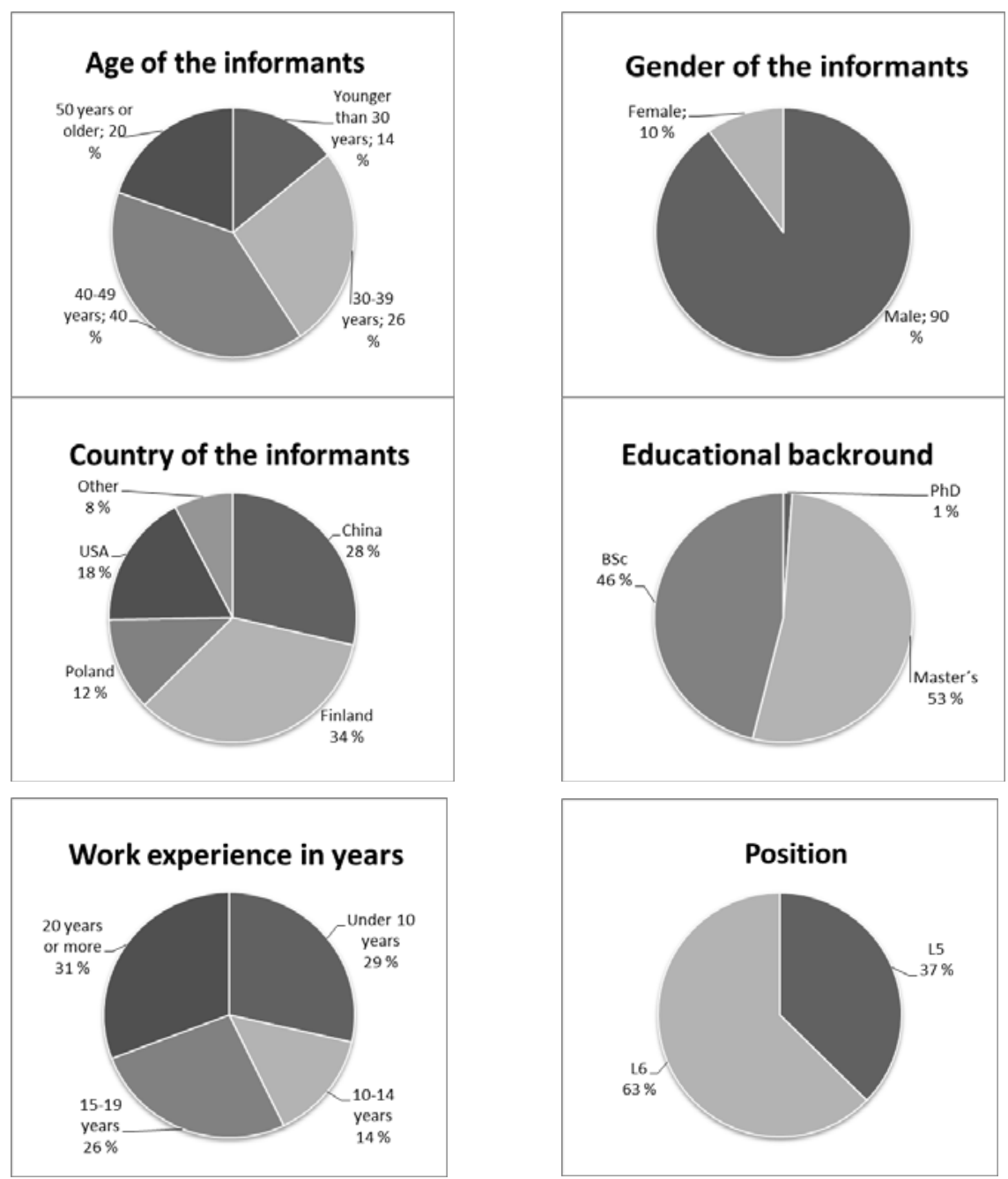


\section{Appendix 3}

Interview data

\begin{tabular}{|c|c|c|c|c|c|}
\hline Country & $\begin{array}{l}\text { Semi-structured } \\
\text { interviews }\end{array}$ & $\begin{array}{l}\text { Number } \\
\text { of pages }\end{array}$ & $\begin{array}{l}\text { Semi-structured } \\
\text { interviews, } \\
\text { leaders }\end{array}$ & $\begin{array}{l}\text { Length of } \\
\text { interview } \\
\text { transcript } \\
\text { (pages) }\end{array}$ & $\begin{array}{c}\text { Workshops, email } \\
\text { reviews of the } \\
\text { results }\end{array}$ \\
\hline \multirow[t]{4}{*}{ USA } & Team A & 8 & Manager A & 9 & \multirow{4}{*}{$\begin{array}{l}\text { All informants } \\
\text { received the } \\
\text { results, had the } \\
\text { option for } \\
\text { comments. }\end{array}$} \\
\hline & Team B & 7 & Manager B & 7 & \\
\hline & Team C & 9 & Manager C & 8 & \\
\hline & (4-6 members/interview) & & & & \\
\hline \multirow[t]{4}{*}{ China } & Team A & 12 & Manager A & 8 & \multirow{4}{*}{$\begin{array}{l}\text { All informants } \\
\text { received the } \\
\text { results, option for } \\
\text { comments. } \\
\text { Personal meeting } \\
\text { with the site } \\
\text { manager. }\end{array}$} \\
\hline & Team B & 7 & Manager B & 6 & \\
\hline & Team C & 8 & Manager C & 6 & \\
\hline & (3-6 members/interview) & & & & \\
\hline \multirow[t]{4}{*}{ Poland } & Team A & 7 & Manager A & 9 & \multirow{4}{*}{$\begin{array}{l}\text { All informants } \\
\text { received the } \\
\text { results, option for } \\
\text { comments. }\end{array}$} \\
\hline & Team B & 8 & Manager B & 7 & \\
\hline & Team C & 8 & & & \\
\hline & (2-4 members/interview) & & & & \\
\hline \multirow[t]{4}{*}{ Finland } & Team A & 7 & Manager A & 9 & \multirow{4}{*}{$\begin{array}{l}\text { Five workshops } \\
\text { ( } 48 \text { participants } \\
\text { from Finland, } \\
\text { China and Great } \\
\text { Britain) }\end{array}$} \\
\hline & Team B & 12 & Manager B & 8 & \\
\hline & Team C & 12 & Manager $\mathrm{C}$ & 8 & \\
\hline & (3-6 members/interview) & & & & \\
\hline
\end{tabular}

\section{Appendix 4}

Themes for semi-structured interviews

\begin{tabular}{|c|c|}
\hline \multirow{2}{*}{$\begin{array}{l}\text { Planning } \\
\text { Virtual team's planning, meeting } \\
\text { and decision making } \\
\text { procedures, communication } \\
\text { infrastructure, rules and norms } \\
\text { for communication, selecting ICT } \\
\text { tools, considering cultural and } \\
\text { professional background }\end{array}$} & $\begin{array}{l}\text { Start: Kick off meeting practices, decision } \\
\text { making, deciding rules and norms for } \\
\text { communication, virtual team building } \\
\text { practices }\end{array}$ \\
\hline & $\begin{array}{l}\text { Working phase: Access to relevant } \\
\text { information, decision making procedures, } \\
\text { support mechanisms for virtual work, } \\
\text { problems and strengths in virtual } \\
\text { communication, virtual meeting practices }\end{array}$ \\
\hline \multicolumn{2}{|c|}{$\begin{array}{l}\text { Lessons learned: Best practices for virtual team's communication, } \\
\text { characteristics of efficient virtual team member, virtual team spirit, } \\
\text { quality of communication, lessons learned practices. }\end{array}$} \\
\hline
\end{tabular}




\section{Appendix 5}

Survey details

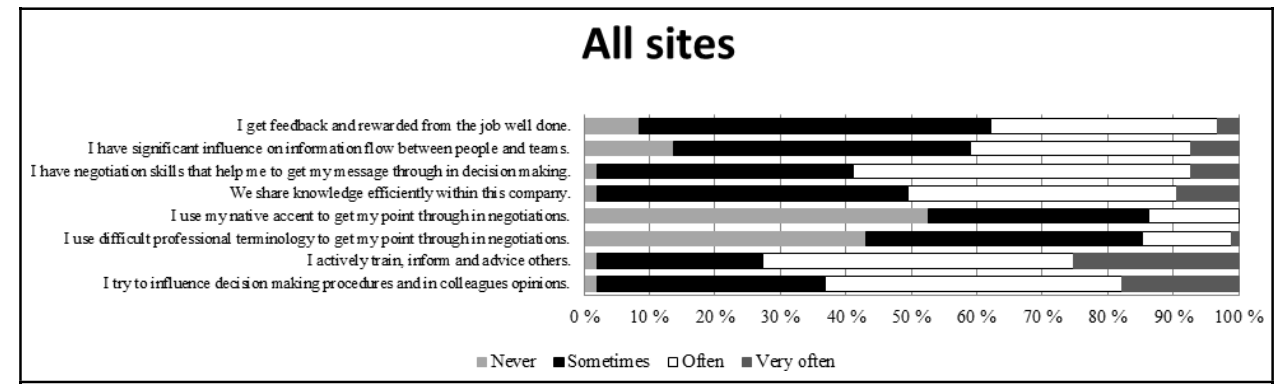

\section{Appendix 6}

Sketch of an organization of the interview and survey participants (see online version for colours)

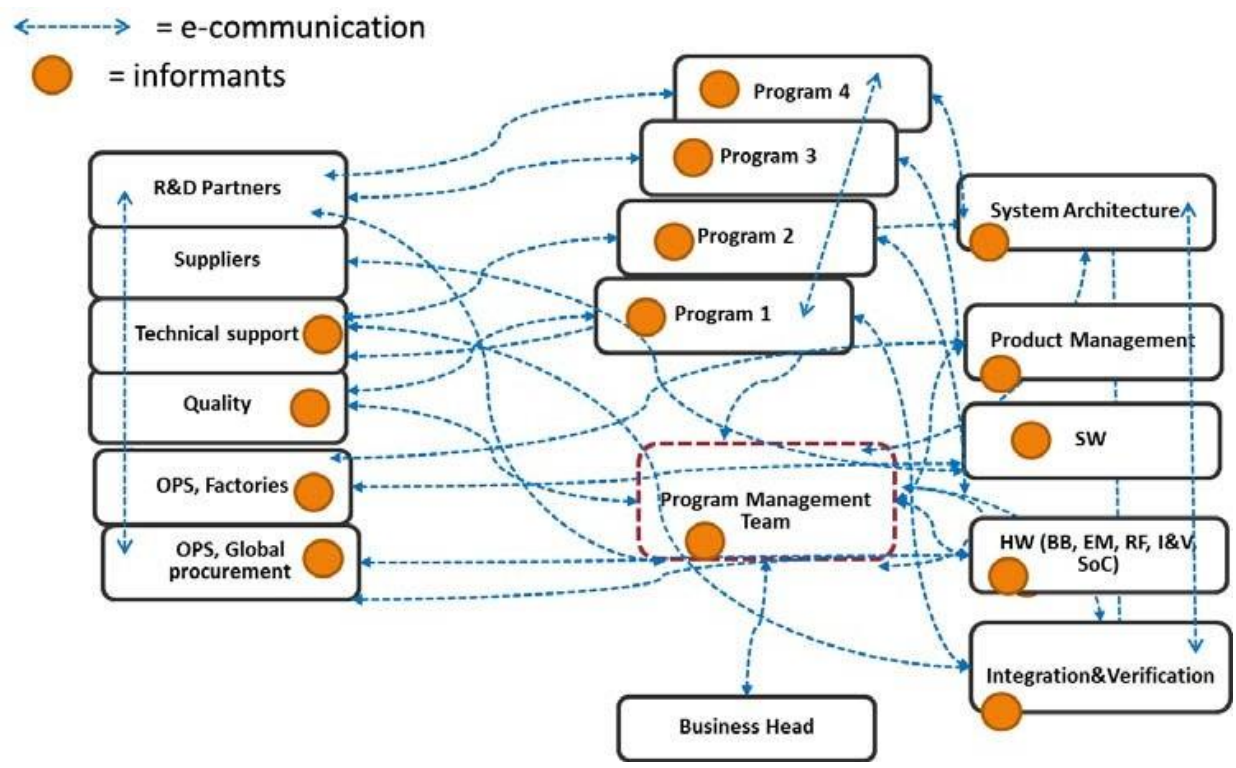

